\title{
HISTÓRIA E MEMÓRIA DO ENSINO SUPERIOR: CAMINHOS DE UMA INVESTIGAÇÃO' ${ }^{1}$
}

\begin{abstract}
Fábio Mansano de Mello²
Ana Elizabeth Santos Alves ${ }^{3}$

\section{Resumo}

O objetivo do artigo é descrever o caminho metodológico de uma investigação científica, no campo da história e memória da educação. O estudo baseou-se em fontes documentais, cujo escopo é uma análise da mercantilização do ensino superior no Brasil, no período de 1995 a 2010. Inicialmente, o artigo apresenta a pesquisa para situar o leitor; em seguida, descreve o método de investigação; na sequência, explica a dinâmica da pesquisa e esclarece os conceitos e as categorias utilizados.

Palavras-chave: metodologia; história e memória; mercantilização da educação; ensino superior.
\end{abstract}

\section{HISTORY AND MEMORY ABOUT HIGHER EDUCATION: WAYS OF INVESTIGATE}

\begin{abstract}
The target of this article is to describe the methodological path of a scientific investigation, in the field of history and memory of education. The study was based on documentary sources whose scope is an analysis on the commercialization of higher education in Brazil from 1995 to 2010. Initially, the article presents the research to situate the reader, then, describes the research method, in the sequence, explains the dynamics of the research from the search and clarifies the concepts and categories used. Keywords: methodology; history and memory; commercialization of education; higher education.
\end{abstract}

\section{HISTORIA Y MEMORIA ACERCA DE LA ENSEÑANZA SUPERIOR: ETAPAS DE UNA INVESTIGACIÓN}

\section{Resumen}

El objetivo del artículo es describir el desarrollo metodológico de una investigación científica, en el campo de la historia y memoria de la educación. El estudio se ha basado em fuentes documentales, cuyo alcance consiste en una análisis de la mercantilización de la enseñanza superior en Brasil, en el período 1995-2010. Inicialmente, se ha hecho la presentación de la investigación para situar el lector; después, se ha descrito el método de investigación; a continuación, se ha explicado el desarrollo de la investigación como también se han dilucidado los conceptos y categorías utilizados.

Palabras clave: metodología; historia y memoria; mercantilización de la educación; enseñanza superior

\footnotetext{
1 Artigo recebido em 30/06/2019. Primeira avaliação em 05/11/2019. Segunda avaliação em 18/12/2019. Aprovado em 12/01/2020. Publicado em 23/01/2020.

2Doutor em Memória (UESB). Docente da Universidade Estadual do Sudoeste da Bahia (UESB), onde leciona Sociologia. Membro do Museu Pedagógico da UESB e do grupo de estudos História, Trabalho e Educação. fabio.m.mello@uesb.edu.br. Orcid: https://orcid.org/ 0000-0003-0244-6017

${ }^{3}$ Doutora em Educação (UFBA). Docente do Programa de Pós-Graduação em Memória, Linguagem e Sociedade (PPGMLS), da Universidade Estadual do Sudoeste da Bahia (UESB). Membro do Museu Pedagógico da UESB e do grupo de estudos História, Trabalho e Educação. Afiliada ao Histedbr. ana_alves183@hotmail.com. Orcid: https://orcid.org/0000-0002-0603-2113
} 


\section{Introdução}

O objetivo deste artigo é descrever o caminho metodológico de uma investigação científica, indicando o método de abordagem e de procedimentos, as categorias e os conceitos utilizados, as dificuldades e os limites encontrados ao longo do desenvolvimento de uma pesquisa. A intenção é compartilhar as experiências com outros pesquisadores, com o intuito de contribuir com o encaminhamento de uma investigação, inspirados nas lições de Charles Wright Mills (1982) sobre o oficio de pesquisador.

Descreve-se o percurso teórico-metodológico de uma investigação no campo da história e da memória da educação, com base em fontes documentais, cujo escopo é o estudo sobre a mercantilização do ensino superior no Brasil, no período de 1995 a $2010^{4}$. As fontes documentais da pesquisa compuseram-se do Relatório do Banco Mundial intitulado "La enseñanza superior: las lecciones derivadas de la experiência"; da Revista Universidade \& Sociedade (RUS), publicada pela Associação Nacional dos Docentes do Ensino Superior (ANDES-SN); e da Revista Estudos (RE), uma publicação da Associação Brasileira das Mantenedoras do Ensino Superior $(\mathrm{ABMES})^{5}$.

Inicialmente apresenta-se a pesquisa, a fim de situar o leitor sobre o estudo; em seguida, descrevem-se o método de investigação e os fundamentos da realização de um estudo com documentos; na sequência, explicam-se a dinâmica da pesquisa a partir da garimpagem e análise das fontes e os conceitos e categorias utilizadas; por último, apresentam-se as considerações finais.

\section{A pesquisa: objetivo, questões e pressupostos}

O objetivo da pesquisa foi compreender como o processo de flexibilização, impulsionado pela Reforma do Estado iniciada em 1995, acarretou aprofundamento

\footnotetext{
${ }^{4}$ Pesquisa realizada no Programa de Pós-graduação Memória: Linguagem e Sociedade da Universidade Estadual do Sudoeste da Bahia (UESB), cujo título é "Memórias acerca da mercantilização do ensino superior (1995-2010): a consolidação da 'universidade flexível'”, realizada pelo doutorando Fábio Mansano de Mello com orientação da Profa . Ana Elizabeth Santos Alves.

${ }^{5}$ Os critérios de inclusão foram os anos de publicação das revistas (entre 1995 e 2010) e temáticas que tratassem de questões referentes à mercantilização do ensino superior e dos impactos sobre o trabalho docente.
} 
da mercantilização do ensino superior. Algumas questões nortearam as análises: o que revelam as memórias sobre a mercantilização do ensino superior? Quais os interesses de classes envolvidos nesse processo? Quais ideologias em disputa afloram nos documentos e como se materializam nas políticas públicas? Quais os impactos da mercantilização do ensino superior sobre a categoria docente? Como o processo de flexibilização materializou-se no ensino superior, implicando novo formato de mercantilização do setor, no período entre 1995 e 2010? Vale ressaltar que essas indagações foram desenvolvidas no trabalho de tese, ao passo que no presente artigo enfatiza-se o percurso metodológico da pesquisa.

A hipótese geral sustenta que, à luz das memórias dos documentos (Relatório do Banco Mundial, Revista Universidade \& Sociedade e Revista Estudos) e da materialização da ideologia nas políticas de ensino superior no período estudado, o discurso da eficiência e da democratização do acesso às "novas" Instituições de Ensino Superior (IES) traduz-se no acirramento da mercantilização do setor e em maior controle e exploração do trabalho docente.

A análise dos documentos permitiu utilizar o conceito de "memórias em disputa", em que a memória aparece, ao mesmo tempo, como uma conquista e um objeto de poder. Entende-se que essa relação está materializada nos documentos centrais da pesquisa: no documento do Banco Mundial, que reproduz a ideologia cujo escopo é naturalizar as relações conflituosas entre as classes sociais, cimentando o estratagema de que o acesso ao ensino superior seria a mola propulsora para a superação das desigualdades sociais, pela imposição, aos países em desenvolvimento, de condicionalidades para a concessão de empréstimos, expressando o ideário neoliberal de ajuste econômico centrado na privatização das empresas estatais e na desregulamentação do mercado; nas revistas do ANDES-SN e da ABMES, em que distintas concepções ideológicas afloram e se apresentam como visões peculiares da realidade do ensino superior brasileiro. Enquanto as primeiras estabelecem críticas às reformas implantadas no setor, as segundas mostram a urgência de as IES particulares se adaptarem às exigências do mercado. Essas proposições não ocorrem de forma linear, acríticas; elas demonstram, em linhas gerais, as ideologias - de projetos distintos - em confronto no terreno da educação superior. 
Estabeleceu-se uma conexão entre os conceitos de memória e de ideologia por se entender que eles não são independentes; são construídos sobre uma base material. Marx (1999) apresenta a perspectiva de que, em primeiro lugar, a produção de ideias está conectada intrinsecamente com a produção material dos homens e, em segundo lugar, com as ideias dominantes de dada sociedade, que são a expressão das classes economicamente dominantes. Se a ideologia dominante procura solidificar seu ideário, apresentando prerrogativas como se fossem neutras, universalmente válidas, a apropriação da memória oficial é fundamental para perpetuar a dominação: "O discurso da unidade e a apologia ao interesse comum asseguram a adesão e a aceitação maciça da ideologia dominante, inclusive, entre as classes dominadas, diretamente prejudicadas por suas determinações" (ANSARA; DANTAS, 2015, p. 9).

Foram analisadas as memórias que emergem dos documentos à luz das totalidades constituídas pelo modo de produção capitalista e das contradições que surgem dessa processualidade histórica. A memória, dessa forma, traz contradições inerentes à própria história, portanto, uma expressão da luta de classes.

$\mathrm{Na}$ busca de respostas às questões levantadas, procurou-se nortear pela noção de que os fenômenos precisam ser compreendidos segundo um método que desvende "o mundo da pseudoconcreticidade" (KOSIK, 1995, p.11), ou seja, considerando que as coisas não se mostram pela aparência; elas são "um claro-escuro de verdade e engano, que, ao mesmo tempo, escondem e revelam a sua essência" (Idem). Buscou-se guiar por uma abordagem de natureza dialética, investigando não somente a representação aparente da realidade, mas, também, a essência. O método proporciona condições de análise das fontes para além da aparência empírica e é nesse processo que se produz conhecimento. Como explica José Paulo Netto (2011), o pesquisador, ao capturar a estrutura e a dinâmica do objeto por meio de procedimentos analíticos, opera a síntese, reproduzindo, no plano do pensamento, a essência do que investigou.

O propósito, ao manusear as fontes documentais citadas, em face do problema de pesquisa formulado e da hipótese de trabalho, foi demonstrar como analisar documentos à luz de uma teoria e que procedimentos metodológicos adotar. ]

\section{O método de investigação}

O desafio teórico-metodológico em face das múltiplas determinações que circundam o objeto consistiu em compreender que o sujeito e o objeto do conhecimento estão imersos em "uma inegável atmosfera sócio-política-cultural" 
(JAPIASSU, 1975, p.10). Esse "enquadramento sócio histórico" do fenômeno a ser investigado mostra que o fazer científico é uma ação humana na qual o conhecimento da realidade ocorre por meio de diferentes leituras de um mesmo fato sócio histórico, de diferentes concepções e pressupostos teórico-metodológicos que confirmam a não neutralidade da ciência. Compreender o objeto no seu movimento histórico "...tal como ele é em si mesmo, na sua existência real e efetiva..." (PAULO NETO, p.20) exclui "qualquer pretensão de neutralidade" (p.10) e implica determinada concepção de método de investigação. Isso mostra que o cientista tem plena consciência do lugar que ocupa e da perspectiva abraçada, como assegura Luiz Costa Pinto:

O astrônomo não é astro, nem o microbiologista é micróbio, mas o antropólogo é homem, o sociólogo é animal como os que ele estuda, assim como o cientista político é cidadão e o economista, necessariamente, ocupa um lugar definido num determinado sistema de produção. O problema, porém, não se resolve, apenas, pela natureza particular dos fatos que se estudam, mas sim pela atitude mental diante deles assumida por aqueles que os estudam. Essa atitude é basicamente condicionada pela estrutura social em que o pensamento se manifesta, pela posição, não raro contraditória, do homem de ciência dentro dessa estrutura e de seu sistema de valores, inclusive dos valores de sua ciência, aos quais the cabe, como cientista, não somente aderir e aceitar, mas também, e sobretudo, fabricar e elaborar com o seu trabalho (COSTA PINTO, 1978, p. 34).

Divergências e contradições teórico-metodológicas entre historiadores, sociólogos, cientistas políticos demarcam o reconhecimento da pluralidade do conhecimento científico. Por exemplo, sobre fatos históricos e sociais encontram-se, no centro do debate, concepções positivistas, para as quais a produção do conhecimento científico deve ser neutra, objetiva, reflexo fiel do fenômeno, imparcial, livre de todo o fato subjetivo e social; concepções ligadas ao presentismo, variante do relativismo subjetivista, que considera a história como uma projeção do pensamento e dos interesses presentes sobre o passado, e, portanto, inconclusa (SCHAFF, 1991, p. 101). Enquanto a concepção positivista se fixa na aparência dos fenômenos, o relativismo absoluto considera que não há verdade objetiva; há várias verdades.

O materialismo histórico, por sua vez, rompe com as concepções anteriores ao ressaltar que os homens fazem a história à luz das condições de vida material, social e política. Nessa perspectiva, "todo conhecimento não é, na verdade, um conhecimento individual e sim de classe" (BUFFA, 1990, p.14). A construção científica é um processo "conflitivo, onde classes sociais contraditórias se afrontam" (FONTES, 
2001, p.119), e os cientistas demarcam posições e estabelecem critérios de verdade. Nesse sentido, é fundamental adotar uma postura metodológica e uma respectiva visão de mundo para não cair em um ponto de vista fragmentado e relativista da realidade. Como explica Michael Lowy (1989, p. 29):

Se admitirmos a tese do marxismo revolucionário segundo o qual toda ciência social é, conscientemente ou não, direta ou indiretamente, "engajada", orientada, "tendenciosa", "partidária", ligada à visão social de mundo, ao ponto de vista de uma classe social, é necessário encontrar uma saída para evitar o desvio do relativismo.

Assim, adotou-se o ponto de vista do método do materialismo histórico, que se orienta por uma concepção de realidade situada na perspectiva da classe trabalhadora, mediada por um processo de "apreender, revelar e expor a estruturação, o desenvolvimento e transformação dos fenômenos sociais" (FRIGOTTO, 2012, p. 164).

Compreende-se que o método de investigação é o caminho que permite, ao pesquisador, interpretar as questões sociais propostas e superar as aparências imediatas do fenômeno, de modo a não perder de vista a sua complexidade. (MORAES,1996). Assim, tomaram-se, como ponto de partida da investigação, os postulados de Marx (GORENDER, 1985, p. XXVI), segundo os quais“(...) o fim último da investigação consiste em se apropriar em detalhe da matéria investigada, analisar suas diversas formas de desenvolvimento e descobrir seus nexos internos." Ou seja, adotar uma reflexão analítica em que se descortinam parte por parte os elementos constitutivos da realidade a ser estudada.

A pesquisa foi realizada com finalidade descritivo-analítica, de caráter qualitativo, tendo como ponto de partida a investigação teórica. Para essa jornada, foi imprescindível analisar a lógica capitalista e a lógica do ensino superior no Brasil contemporâneo, mediante debate com autores que aprofundam o conhecimento sobre o tema. O material básico para essa atividade foram livros, revistas, periódicos e textos eletrônicos.

Entre as técnicas de coleta de dados, utilizou-se a análise documental (registros, documentos e sites) para agregar informações e delimitar o problema. Os documentos selecionados, citados na introdução, expõem questões referentes à mercantilização do ensino superior e aos impactos sobre o trabalho docente. Para a análise documental, utilizaram-se subsídios teórico-metodológicos peculiares à tradição materialista, de acordo com Shiroma, Campos e Garcia (2005), Noma, 
Koepsel e Chilante (2010) e Evangelista (2014). Em linhas gerais, as autoras advogam a ideia de que é necessário compreender as mensagens presentes nos documentos, superando os aspectos mais aparentes e fenomênicos do conteúdo. Os textos dos organismos multilaterais sobre política educacional deveriam ser interpretados e correlacionados com uma literatura interdisciplinar, para que se pudesse abarcar o contexto social das mensagens e apreender a dimensão política, que apresenta diagnósticos, prioridades e orientações aos países que incorporam tais propostas. Significativo também deveria ser o cuidado em analisar os conceitos mais evidentes e vasculhar o texto, porque o intuito era capturar os silenciamentos, o que está oculto e metamorfoseado nas diretrizes aparentemente cristalinas.

Levando em consideração que a realidade não se revela de forma imediata, não basta a simples leitura para a apreensão dos conteúdos e para a atribuição de significados aos documentos de políticas educacionais. Aparência e essência, elementos de um mesmo fenômeno, não são coincidentes e, para desvendá-los, torna-se necessário utilizar instrumentos que possibilitem o desvelamento da essência dos fenômenos. Não estamos a afirmar que, para a explicação da realidade social, não se pode ter início com o que é aparente e empírico. Estamos salientando que se fixar apenas na aparência é insuficiente para atingir a essência, para tal, deve-se buscar a relação dialética existente entre essência e fenômeno (NOMA et al., 2010, p. 67).

Segundo Shiroma, Campos e Garcia (2005), as recomendações dos documentos dos organismos multilaterais não eram prontamente assimiladas e postas em prática. Cada país ou região deveria elaborar estratégias distintas de interpretação, de acordo com a realidade. Logo,

tal processo implica, de certo modo, uma reescritura das prescrições, - que coloca para os estudiosos a tarefa de compreender a racionalidade que os informa e que, muitas vezes, parece contraditória, fomentando medidas que aparentam ir em direção contrária ao que propõem (2005, p. 430-1).

Da interpretação e contextualização dos conceitos presentes nos textos, aflora a ideia fundamental que justifica toda a reforma da estrutura educacional: a perspectiva da crise. Para superá-la, apoiam-se no ideário e nas estratégias empresariais, por isso a utilização de palavras como flexibilidade, gestão, parcerias, investimentos, colaboração, recursos, monitoramento, avaliação, entre outras. Segundo SHIROMA; CAMPOS; GARCIA (2005, p. 438) esses conceitos "evidenciam 
não apenas a penetração da ideologia do gerencialismo na educação, mas expressam também a conformação e produção de um novo 'léxico' educacional, um híbrido de pedagógico e gerencial".

Os relatos dos autores dos textos das revistas analisadas propiciam uma visão sobre as transformações ocorridas no ensino superior brasileiro, no período de 1995 a 2010. Mais do que isso, as memórias presentes nesses documentos revelam, de maneiras distintas, a forma como a flexibilização esteve presente nas ideologias, as concepções e os processos de trabalho descritos. As próprias memórias estão repletas de ideologias, pois expressam dada concepção de realidade social e um compromisso político com essa realidade. Conforme assegura Jelin, a reflexão sobre memória "raras veces puede ser hecha desde afuera, sin comprometer a quien lo hace, sin incorporar la subjetividad del/a investigador/a, su propia experiencia, sus creencias y emociones. Incorpora también sus compromisos políticos y cívicos" (2012, p. 37).

O fundamental na análise era reconstruir historicamente, a partir de uma particularidade de determinado campo empírico, "a relação contraditória entre o universal, o particular e o singular" (MORAES, 1996, p. 264). Como também alerta Gaudêncio Frigotto (2015, p.118) tomar o "objeto na inseparável relação entre o estrutural e o conjuntural" - este foi o maior desafio. A superação desse desafio implicou pensar o objeto no seu movimento real, ao considerar o fato de os homens terem uma consciência que se manifesta pela ação da linguagem nas relações sociais (MARX e ENGELS 2007, p. 32-34) e permite fazer abstrações do mundo que os cerca. A análise das fontes ${ }^{6}$ remeteu a outro plano de questões, as quais serão consideradas a seguir.

\section{Os documentos: garimpagem das fontes, conceitos-chaves e categorias}

Primeiro, vale esclarecer que um documento guarda conhecimentos sobre fatos ou acontecimentos e que o mais importante é lembrar, segundo Jacques Le Goff (1993), que o seu conteúdo "não é inocente". É um instrumento que o pesquisador

\footnotetext{
${ }^{6}$ As fontes estudadas foram as diretrizes do Banco Mundial para a reforma do ensino superior no país; artigos publicados em revistas com textos científicos escritos por intelectuais que consideram que a universidade deve obedecer à lógica do mercado e artigos com a visão de intelectuais que criticam as reformas neoliberais na educação superior.
} 
não domina e, portanto, o exame pode levar a vários caminhos de pesquisa, a novas e diferentes interpretações ou mesmo a modificações dos pressupostos utilizados pelo pesquisador. (CELLARD, 2008).

O segundo destaque refere-se à dinâmica e ao movimento interno da pesquisa. Entende-se que, à medida que se avança nas questões teóricas e na análise do documento, surgem indagações que não estavam elencadas no projeto original e, orientadas pelo método, obrigam a rever conceitos e a redirecionar os objetivos da investigação. O desenvolvimento de uma pesquisa requer o cultivo da capacidade imaginativa para aprimorar a percepção acerca da articulação entre categorias, conceitos e objeto de estudo no manuseio dos documentos (OLIVEIRA, 1998).

Quando se examina o documento que relata as diretrizes do Banco Mundial, observa-se que essa fonte central da agência multilateral se tornou insuficiente para capturar as memórias em disputa no plano ideológico acerca do ensino superior. Isso mostra que a pesquisa documental requer o reconhecimento de outras fontes de informações em torno do objeto de pesquisa e dos questionamentos (CELLARD, 2008). Recorreu-se, por isso, à análise dos textos das duas revistas citadas, com orientações políticas distintas, para que, então, se pudessem apreender as distintas visões de realidade social materializadas nesses textos.

O terceiro destaque diz respeito às bases históricas com as quais está conectado o objeto da pesquisa. Novamente o método orientou para que se captasse o fenômeno da mercantilização do ensino superior não de forma isolada, mas conectada com as determinações do modo de produção capitalista. Cabe ao investigador compreender a dinâmica das relações sociais e articulá-las ao modus operandi da lógica burguesa de acumulação. Sérgio Castanho (2010, p. 11) explicita o esforço de Marx no século $\mathrm{XIX}$ para encontrar as leis tendenciais do desenvolvimento histórico. Essas leis demonstravam uma direção de desenvolvimento, e não uma forma apriorística de conhecimento da realidade. "É por isso que a teoria da história marxiana não é uma gaiola onde se aprisiona a realidade, mas uma referência analítica ressaída do trato com a realidade social no tempo".

Nessa perspectiva, constatou-se, no exame crítico dos documentos, que a mercantilização do ensino superior não é algo novo, inédito. O fenômeno já aparecia na década de 1960, com a reforma universitária proposta pelos militares. A face mercantil e privatista do setor a partir da década de 1990 precisou ser estudada em 
conexão com a reforma do Estado brasileiro. Essa redefinição significa que o Estado deixou de ser responsável direto pelo desenvolvimento econômico e social e passou a se concentrar na esfera da promoção e regulação desse desenvolvimento. Concomitante às mudanças do aparelho de Estado brasileiro, houve, em dezembro de 1996, a promulgação da Lei de Diretrizes e Bases da Educação Nacional (LDBEN), à luz das recomendações do Banco Mundial presentes no documento "La enseñanza superior: las lecciones derivadas de la experiência” (1995). A LDBEN trouxe uma ideologia privatista no momento em que normatizou, por exemplo, a diferenciação de cursos e a diferenciação de instituições.

A reforma do Estado, por sua vez, está intimamente ligada a um processo global de revitalização do capitalismo, que teve as taxas de lucros diminuídas com o modelo taylorista-fordista de produção. O que se viu, a partir do fim da década de 1970 e início de 1980, foi uma nova estrutura organizacional industrial, acompanhada de uma onda de transformações nas esferas política e social. David Harvey denomina de "acumulação flexível" esse regime de acumulação capitalista e assim a descreve:

A acumulação flexível, como vou chamá-la, é marcada por um confronto direto com a rigidez do fordismo. Ela se apoia na flexibilidade dos processos de trabalho, dos mercados de trabalho, dos produtos e padrões de consumo. Caracteriza-se pelo surgimento de setores de produção inteiramente novos, novas maneiras de fornecimento de serviços financeiros, novos mercados e, sobretudo, taxas altamente intensificadas de inovação comercial, tecnológica e organizacional. A acumulação flexível envolve rápidas mudanças dos padrões do desenvolvimento desigual, tanto entre setores como entre regiões geográficas, criando, por exemplo, um vasto movimento no emprego no chamado 'setor de serviços' (2004, p. 140).

A acumulação flexível reorganizou a produção industrial, potencializou a precarização do trabalho, flexibilizou a produção de mercadorias e permitiu (considerável) expansão do setor de serviços. O ajuste global das relações capitalistas demandou reformas nos mais variados setores da sociedade, cujo escopo foi a ampliação dos mercados e a reestruturação do espaço social no que se refere ao campo de atuação das esferas pública e privada. Para Vera Chaves (2010, p. 484), essa processualidade incide diretamente sobre a educação superior:

Esse conjunto de fatos impõe uma ressignificação ao processo educativo, no campo das concepções e das políticas, cuja expressão maior, na América Latina, se concretizou nos anos 1990, a partir de um movimento reformista, orientado pelos organismos internacionais, como o Fundo Monetário Internacional e o Banco Mundial. 
Ao apresentar as especificidades desse tipo de mercantilização do ensino superior, mostrou-se a importância de se relacionar o fenômeno estudado com as determinações históricas de média e curta durações a fim de explicitar os nexos dessa relação. Isso levou a entender o objeto como parte de uma totalidade histórica "...onde se estabelecem as mediações entre o campo da particularidade e sua relação com uma determinada universalidade" (FRIGOTTO, 2012, p. 118).

Portanto, a categoria totalidade, primeira categoria analítica utilizada, permitiu conectar o processo de mercantilização do ensino superior com uma teia mais ampla de consolidação e reestruturação das relações capitalistas de produção, mediante análise da relação entre o singular e o universal. Ivo Tonet (2013, p. 96) enfatiza a relação dialética entre o todo e as partes, ainda que o todo seja essencial do ponto de vista do conhecimento. Além disso, assegura que a noção de totalidade é marcada por contradições e mediações que determinam o movimento próprio de cada fenômeno, constituindo suas especificidades. Nas palavras do autor:

Totalidade, portanto, como princípio metodológico, significa que nada pode ser compreendido de modo isolado. O sentido de cada parte, de cada fato, de cada dado só emerge na medida em que ele for apreendido como momento de um conjunto, como resultado de um processo através do qual cada um dos elementos parciais vai adquirindo a sua natureza e a sua especificidade. Trata-se, pois, de apreender o processo através do qual vão se constituindo, ao mesmo tempo, a totalidade de determinado objeto e as partes que o compõem, a hierarquia e a ordem entre os diversos momentos, o modo como se relacionam entre si o todo e as partes, sob a regência do primeiro, as relações das diversas partes entre si e a passagem de um momento a outro (TONET, 2013, p. 116).

Para Karel Kosik (1995), a perspectiva da totalidade permite ao pesquisador compreender a essência do fenômeno, superando as formas fetichizadas e aparentes. Em outras palavras, a totalidade concreta é um processo indivisível formado pelos seguintes momentos: a) superação da aparência do fenômeno e conhecimento de sua objetividade; b) apreensão do caráter histórico e transitório do fenômeno; e c) conhecimento do conteúdo objetivo do fenômeno (1995, p. 61). Segundo o autor, "a economia não é apenas a produção de bens materiais; é ao mesmo tempo produção das relações sociais dentro das quais esta produção se realiza" (1995, p. 191). Sua referência é Marx (1983) que, ao discutir o método da economia política, expôs o movimento de apreensão do real afirmando que "o concreto é concreto por ser a síntese de múltiplas determinações, logo, unidade da diversidade" (1983, p. 218). 
concreto apresenta-se para o pensamento em um processo de síntese, no qual "as determinações abstratas conduzem à reprodução do concreto pela via do pensamento" (1983, p. 219).

Maria Ciavatta (2014, p. 194-195) analisa o caráter histórico da totalidade, que não deve ser associado a determinadas distorções, como a aproximação semântica com o totalitarismo - seja de direita ou de esquerda -, que implica cerceamento da dignidade humana, nem à ideia de que a totalidade abarcaria a compreensão de tudo. Sobre a construção histórica do conhecimento, afirma a autora:

Concebemos a realidade não como um sistema estruturado em si mesmo, mas como uma totalidade histórica, socialmente construída. É a realidade na dinâmica de seus processos, nas suas leis mais íntimas, que revela, sob a aparência dos fenômenos, as conexões internas e necessárias. Totalidade não significa todos os fatos, e todos os fatos reunidos não constituem uma totalidade. O conhecimento dos fatos isolados, mesmo quantificados, é insuficiente para explicar o todo (CIAVATTA, 2014, p. 203).

A segunda categoria analítica que norteou o exame das fontes foi a contradição, que, por seu turno, refere-se à própria dinâmica do capital que, na ânsia de valorização, cria-destrói-recria condições de exploração - uma contradição centrada na relação antagônica entre capital e trabalho. Ao explicar a processualidade das contradições, Frederico Mazzucchelli (1985) afirma que o capital tem uma tendência para a superprodução, de um lado, e para a negação do trabalho vivo, de outro, e adianta as consequências desse metabolismo, seguindo os passos de Marx: "As contradições imanentes da produção capitalista sempre se exteriorizam e se 'resolvem' nas crises, para serem repostas mais adiante, já que são constitutivas desse modo de produção" (1985, p. 22). No que tange à explicação da superprodução como característica intrínseca do capitalismo, recorre a esta explanação de Marx:

A contradição, expressa em termos gerais, consiste em que, de uma parte, o regime capitalista de produção tende ao desenvolvimento absoluto das forças produtivas, prescindindo do valor e da mais-valia nele implícitos e prescindindo também das condições sociais dentro das quais se desenvolve a produção capitalista, enquanto, por outra parte, tem como objetivo a conservação do valor-capital existente e sua máxima valorização (MARX apud MAZZUCCHELLI, 1985, p. 30).

Segundo Mazzucchelli, o conflito gerado pela produção desenfreada de mercadorias e pela realização desses produtos na forma de valores materializa-se nas crises, o que "significa ao mesmo tempo a existência de uma massa de mercadorias 
que não alcançou sua conversão em dinheiro, ou de uma massa de valores de uso que não se realizou como valor" (1985, p. 32). A respeito do que denomina redundância do trabalho vivo, o autor explica de que maneira o capital se desenvolve e nega seu fundamento, o trabalho. Com o desenvolvimento das forças produtivas, 0 tempo de trabalho socialmente necessário é frequentemente reduzido com a finalidade de ampliar o tempo de trabalho excedente, o que "envolve uma abrupta contradição, já que o capital tende a negar a base sobre a qual se apoia a produção de valores e, portanto, a própria valorização" (1985, p. 33).

Nessa direção, atentou-se para as contradições que emergiram do objeto de pesquisa, a mercantilização do ensino superior, uma vez que o movimento da realidade permitiu aproximar esse fenômeno das determinações gerais da sociabilidade capitalista. Assim, a compreensão das categorias totalidade concreta e contradição foi fundamental para analisar o objeto de pesquisa nas suas múltiplas determinações, considerando a dinâmica da sociedade burguesa e as contradições que registram as contínuas transformações dessa sociedade, porquanto a natureza das contradições "...seus ritmos, as condições de seus limites, controles e soluções dependem da estrutura de cada totalidade - e, novamente, não há fórmulas/formas apriorísticas para determiná-las: também cabe à pesquisa descobri-las" (PAULO NETTO, 2011, p. 57).

A continuidade da análise das fontes, tendo em vista o fenômeno investigado, foi norteada por conceitos ordenados no confronto com a leitura dos documentos e as fontes bibliográficas: os conceitos de mercantilização e flexibilização e memórias em disputa.

A compreensão do processo de transformação da educação em mercadoria depende, necessariamente, da compreensão da tendência histórica do capitalismo de transformar bens materiais ou simbólicos em produtos cambiáveis. Assim, revisitouse a obra de Marx, sobretudo o Manifesto do Partido Comunista (1997) e O Capital (1982). Na ânsia pela autovalorização, o capital "esteriliza" certos trabalhos e se reconstitui integrando produtos que outrora não estavam sob sua égide. Esse fenômeno pode ser correlacionado à educação, em especial ao ensino superior. Quando se vende um curso de graduação, na contratação de professores e funcionários, no uso de tecnologias, como ocorre na educação a distância, no desenvolvimento de softwares e hardwares educacionais, na articulação com o 
Estado, no fornecimento de bolsas de estudos, na fusão de empresas educacionais e na venda de ações na bolsa de valores, entre outros procedimentos, corrobora-se a ideia de que o ensino superior está conectado com as determinações gerais da acumulação capitalista, sujeito, portanto, à mercantilização.

O conceito de flexibilização, que se adotou com base na discussão teórica de David Harvey (2004) acerca da acumulação flexível, se refere aos ajustes do capital com a finalidade de potencializar os lucros. O conceito de "universidade flexível" diz respeito à nova configuração do ensino superior brasileiro não somente quanto às transformações estruturais das instituições públicas, advindas das determinações de organismos multilaterais, mas, principalmente, no tocante à educação-mercadoria que é vendida pelas instituições privadas, consolidando a perspectiva da educação como um negócio que atua na formação específica de uma mão de obra flexível para o mercado de trabalho.

Dessa forma, o método de investigação consistiu em analisar os documentos, ante as questões de pesquisa, tendo a clareza de que os autores os produziram com propósitos diferentes. Ato contínuo coube interpretar as contradições internas dos dados à luz das categorias (totalidade e contradição) e dos conceitos (mercantilização e flexibilização).

Diferentes perspectivas ideológicas encontram-se materializadas nos documentos. Concorda-se com Marx, quando condiciona a produção ideológica de uma época à correspondente classe dominante:

As ideias dominantes nada mais são do que a expressão ideal das relações materiais dominantes concebidas como ideias; portanto, a expressão das relações que tornam uma classe a classe dominante; portanto, as ideias de sua dominação (MARX, 1999, p.72).

Acredita-se que os registros documentais devem ser analisados e contextualizados no terreno da luta de classes, uma vez que, de um lado, as classes dominantes constroem estratégias de estruturação e divulgação de seu ideário político de forma unilateral; de outro, as classes exploradas lutam pela exposição do contraponto ideológico dominante, expondo as contradições e permitindo reflexões sobre outra realidade possível. Ao analisar as revistas do ANDES-SN e da ABMES, distintas concepções ideológicas afloram e se apresentam como visões peculiares da realidade do ensino superior brasileiro. Enquanto as primeiras estabelecem críticas às 
reformas implantadas no setor, as segundas mostram a urgência das IES particulares de se adaptarem às novas exigências do mercado.

\section{A análise das fontes e a lógica interna dos textos}

O mapeamento das fontes foi ordenado para que se desenvolvesse uma "crítica epistemológica e ideológica" dos documentos, objetivando construir uma historiografia da história da educação, como ensina Mirian Jorge Warde (1990). Uma crítica dirigida pela concepção de que a ciência é histórica e condicionada às visões de mundo das classes sociais, uma vez que as implicações político-ideológicas dos sujeitos no domínio da natureza impactam diretamente as lutas de classes (LOWY, 1989, p.15). A apreensão do objeto pelo sujeito, no processo de produção do conhecimento de dada realidade, é abstraído objetivamente por "um indivíduo histórico que exerce a sua atividade prática no trato com a natureza e com os outros homens, tendo em vista a consecução dos próprios fins e interesses, dentro de um determinado conjunto de relações sociais" (KOSIK, 1995, p. 9-10). Assim, na análise das fontes guiou-se pelo princípio segundo o qual o pesquisador é um sujeito social e histórico com compromisso político imbricado no processo de construção do conhecimento. As reflexões acerca das fontes implicaram analisá-las na sua condição histórica e como perpetuação da memória das lutas de classes sobre dada concepção de realidade social e compromisso político com essa realidade.

A flexibilização está assim explicitada nos ditames do Banco Mundial para que os países subdesenvolvidos saiam da "condição subalterna": condicionalidades impostas no financiamento, eliminação de barreiras alfandegárias, redução de direitos sociais, flexibilização da força de trabalho, política de privatizações, intervenção do capital financeiro, entre outros. No caso do ensino superior, está presente a ideologia de "desenvolvimento", "modernização" do setor, materializada nos cursos de curta duração, no ensino tecnológico e na educação a distância. Os autores da Revista Universidade e Sociedade (RUS) reconhecem esse encaminhamento das políticas públicas como uma aderência à lógica da acumulação e à transformação contínua da educação em mercadoria. Por outro lado, a estruturação da reforma universitária é tratada pela Revista Estudos (RE) como sinônimo de "nova gestão universitária" e de 
necessidade de as IES se organizarem para atender às demandas da "cultura empreendedora".

Os autores contrários à reforma neoliberal criticam a chamada "flexibilidade administrativa" proposta pelo governo $\mathrm{FHC}$, por entenderem que as metas e os objetivos apresentados estariam mais próximos de uma gerência empresarial, que haveria redução do controle do Estado sobre o setor e que seriam abertas as portas para a iniciativa privada. Na Revista Estudos, essa flexibilidade administrativa está devidamente incorporada à gestão das IES, na medida em que utiliza os conceitos de inovação, concorrência, motivação, empreendedorismo, colaboração etc. Enquanto a RUS critica a redução dos investimentos na educação pública, a RE considera a redução de custos das IES privadas uma ação fundamental para manter os negócios.

Se a "modernização" do ensino superior significa flexibilidade para acompanhar a lógica do mercado, para a RUS o resultado desse processo é uma nova face do imperialismo, uma cultura de avaliação com critérios de produtividade e eficiência, em detrimento da qualidade do ensino, além de naturalização da tendência privatista da educação, sucateamento das IES públicas e desqualificação e precarização do trabalho docente. Segundo a RE, a "modernização" está presente na cultura empreendedora adotada pelas IES, na busca pela diversificação de receitas, suposta descentralização da gestão, grade curricular flexível, critérios de inovação e eficiência da direção acadêmica e perfil proativo dos docentes. $O$ caso dos centros universitários é um exemplo pontual desses olhares divergentes. O que, para os autores da RUS, representa uma flexibilização nefasta da educação superior, condição em que o Estado pretende transformar a universidade em empresa, para a Revista Estudos significa uma rápida adaptação da universidade ao mercado, contribuindo para a consolidação de um ensino superior democrático e plural no país.

A flexibilização do ensino superior, conforme se analisou, engendra diversas contradições inerentes ao movimento de adequação entre educação e mercadoria, processo em que se deve chamar a atenção para o papel do Estado. Nas conexões entre ensino superior e interesses do grande capital, vê-se emergir, das memórias dos documentos, o conceito "democratização" do ensino, que mais confunde do que explica a realidade da educação superior no país.

Na concepção da RUS, a democratização do ensino superior está diretamente relacionada com a mercantilização, ou seja, com a transformação da educação em 
mercadoria a ser consumida pelo aluno-cliente. Essa postura do Estado se traduz na tendência de aumentar o controle e diminuir o investimento no setor. Os textos sobre o Programa Universidade Para Todos (ProUni) revelam a "camuflagem democrática" que privilegia investimentos públicos no âmbito privado, enquanto as IES públicas sofrem constantes cortes no orçamento. Trata-se, portanto, de uma pseudo democratização. De acordo com a RE, o olhar da "democratização" do ensino superior está próximo ao da "inclusão social", pois as IES privadas se consolidaram como porta principal do ensino superior a uma grande parcela de estudantes, além de dar oportunidades aos filhos das classes trabalhadoras com a concessão de bolsas de estudos. Mais do que isso, revela o novo modelo gerencial das IES, que agora agem com "responsabilidade social", sugerindo o caráter público do ensino privado. Assim. o Estado é criticado pelos empresários quando, com a burocratização do sistema, exerce forte controle sobre o setor, mas é enaltecido quando financia os projetos e a expansão do ensino privado.

A flexibilização que se materializa no trabalho docente também revela diferentes percepções. Segundo a RUS, a precarização do trabalho docente é uma expressão da dinâmica capitalista para potencializar lucros, cujos impactos no chão da escola refletem a intensificação e a rotinização do trabalho. Essa realidade é capturada de forma diversa pela revista das mantenedoras das IES privadas (RE), a qual entende que a organização do trabalho, o trabalho em equipe, a motivação dos alunos, a participação ativa na escola, o domínio de novas tecnologias, o envolvimento da escola com a comunidade etc., enfim, o desenvolvimento de outras tantas funções, além da docência, são características do "professor empreendedor".

A incorporação acrítica da racionalidade técnica do capital ao ensino superior confluiu no produtivismo acadêmico, um fenômeno em que eficiência é a palavrachave. Se as memórias dos autores críticos salientam o controle sobre o trabalho docente e a dinâmica da linha de montagem para os produtos da ciência, as memórias dos apologistas da iniciativa privada consideram que a adequação da IES ao mercado é uma saída à crise do setor, tendo em vista a concorrência entre as instituições. Dessa forma, ocorre não somente o incentivo à produtividade acadêmica, mas, sobretudo, a necessidade de diversificação dos produtos oferecidos aos consumidores. Trata-se de parcerias e convênios das IES com instituições privadas 
ou estatais, consultorias e assistências profissionais que gerem receitas, concedam bolsas para docentes e discentes e divulguem a marca da empresa educacional.

A iniciativa privada exige o perfil do professor empreendedor, que "vista a camisa dos alunos", que busque parcerias com outras instituições, que demonstre competências e habilidades inovadoras, além de conhecimento científico, ético, estético e outras tantas qualidades requeridas na profissão. A ideologia que valoriza esse professor ideal (para o mercado e para o lucro das IES privadas) não leva em conta a carga horária do profissional, as múltiplas funções que desempenha, a relação entre ensino e pesquisa, as peculiaridades no processo avaliativo dos alunos... Enfim, a própria docência é posta em segundo plano.

Em face do exposto, compreende-se que as memórias estabelecem uma disputa pelo consenso social, além de referendar certa visão de mundo:

\begin{abstract}
Las memorias son procesos subjetivos e intersubjetivos, anclados en experiencias, en "marcas" materiales y simbólicas y en marcos institucionales. Esto implica necesariamente entrar enel análises de la dialéctica entre individuo/subjeticidad y sociedad/pertenencia a colectivos culturales e institucionales. Las memorias, siempre plurales, generalmente se presentan en contraposición o aun en conflicto com otras. Al trabajar sobre luchas o conflictos al rededor de memorias, el acento está puesto en el rol activo de quienes participan en esas luchas. Las relaciones de poder y las luchas por la hegemonia están siempre presentes. Se trata de una lucha por "mi verdad", com promotores/as y "empreendedores/as", com intentos de monopolización y de apropiación. El enfoque propuesto reconoce el caráter construido y cambiante de los sentidos Del pasado, de los silencios y olvidos históricos, así como del lugar que sociedades, ideologías, climas culturales y luchas políticas asignan a la memoria. De ahí la necesidad de "historizar" la memória (JELIN, 2012, p. 25).
\end{abstract}

Não menos importantes são as questões referentes às classes sociais que despontam na medida em que se analisam as reformas do ensino superior. A organização do Estado brasileiro atende a uma demanda histórica do modo de produção capitalista, já que as determinações políticas e econômicas se fundem com os interesses das classes dominantes. Além da preponderância econômica, o Estado constrói um arcabouço ideológico na sociedade para legitimar as reformas, e mais, colocar essa necessidade reformista como a única saída para as crises de acumulação.

Um caráter contraditório dessa processualidade aparece na ideologia do Estado mínimo, em que a iniciativa privada - as leis do mercado - teria preponderância sobre as atividades estatais julgadas ineficientes. Um debate acerca 
da relação entre o público e o privado instaura-se, ou seja, quais outras esferas garantiriam serviços de qualidade para os cidadãos-consumidores? Essa questão ganha contornos de luta de classes na medida em que estão em jogo a estrutura social e suas representações, porquanto o predomínio do privado não está limitado à educação, mas estende-se à saúde - vide a mercantilização dos planos de saúde -, ao transporte, ao lazer, à previdência social, à segurança, enfim, à complexidade da vida social. Se se tirar o pano de fundo das classes sociais, esse terreno se consolida em termos de qualidade/eficiência, mascarando o binômio conquistas-direitos sociais.

A partir da década de 1990, assiste-se à consolidação de um Estado forte o suficiente para reduzir investimentos em políticas sociais e, seguindo as orientações do capitalismo internacional, fortalecer seu papel de agente do mercado articulandose à totalidade capitalista. Exemplo dessa articulação no ensino superior é a expansão, em larga medida, das IES privadas, com a anuência, o financiamento e o controle do Estado. Nessa perspectiva, os interesses das várias frações burguesas que estão em disputa por novas fatias do mercado educacional fundem-se com os interesses da agência estatal. No momento em que o Banco Mundial orienta e, de certa forma, determina regras para o desenvolvimento do ensino superior, não se trata de uma imposição vertical para as políticas públicas nacionais, mas de um acordo entre parceiros, com interesses em comum, que visam ampliar o poderio políticoeconômico sobre o conjunto da sociedade.

A burguesia nacional referenda as estratégias internacionais com pactos que redefinem rotas lucrativas para o setor. Isso não exclui, por certo, o caráter imperialista do Banco Mundial em face dos "países em desenvolvimento", como o Brasil. Esse fenômeno ocorre com a articulação das tendências gerais do mercado global com os esforços dos governos em aumentar a produtividade e a competitividade, no intuito de superar as crises e a estagnação econômica. As recomendações de agências como FMI e BM são inequívocas e fundamentais para restabelecer a suposta harmonia do mercado, demarcando sua influência sobre as demais economias.

\section{Considerações finais}

Demonstrou-se, neste artigo, a importância de análise dos documentos para desvendar as variadas visões de mundo materializadas nos respectivos conteúdos. Guiado pelo método do materialismo histórico, pôde-se conectar as diretrizes do 
Relatório do Banco Mundial e as ideologias presentes nas revistas com a dinâmica da sociedade capitalista.

$\mathrm{Na}$ análise dessa processualidade histórica, afloraram as mediações entre 0 ensino superior e a lógica da acumulação burguesa. Verificou-se que o Estado é o principal ator no cenário das reformas, cujo objetivo é o de cimentar as bases para que a reestruturação produtiva se consolide e o capitalismo ganhe fôlego em suas investidas em prol da autovalorização. Uma dessas faces é a mercantilização do ensino superior, que não apenas limita a presença do Estado no setor, mas abre um nicho extremamente rentável para que a iniciativa privada o explore e fortaleça a prerrogativa de que o mercado favorece a democratização do ensino.

Verificou-se também a transformação do trabalho docente com a precarização do ofício: nas IES públicas, contingenciamento de recursos e intensificação do trabalho graças ao produtivismo acadêmico; nas IES privadas, o docente é um "colaborador", que vê seu trabalho ganhar contornos de "empreendedorismo".

Os documentos mostram os interesses de classes no que tange as reformas educacionais. O Estado brasileiro configurou-se atendendo a uma demanda histórica do modo de produção capitalista, já que suas determinações políticas e econômicas se fundem no interesse das classes dominantes. Além de sua preponderância econômica, o Estado constrói um arcabouço ideológico na sociedade para legitimar as reformas, e mais, colocar essa necessidade reformista como a única saída para as crises de acumulação.

Concluímos que os documentos analisados revelaram as diferentes memórias em disputa acerca do ensino superior, mediante proposições e silenciamentos, o que permitiu, no esforço intelectual, relacionar um fenômeno social às determinações mais gerais da sociabilidade capitalista. Ademais, ficou demonstrado que documentos escritos constituem fonte valorosa de reconstrução histórica no campo da história da educação, embora exijam do pesquisador uma análise em profundidade dos textos para não cair nas "inúmeras armadilhas" (CELLARD, p. 296) que eles escondem. 


\section{Referências}

ANSARA, Soraia; DANTAS, Bruna Suruagy do Amaral. Aspectos ideológicos presentes na construção da memória coletiva. Revista Athenea Digital, São Paulo, n. 15, março de 2015.

BANCO MUNDIAL. La enseñanza superior: lecciones derivadas de la experiência. Washington,1995. Disponível em http://firgoa.usc.es/drupal/files/010-1344Sp.pdf Acesso em 02/05/2016.

BUFFA, Ester. Contribuição da História para o enfrentamento dos problemas educacionais contemporâneos. Revista Em Aberto, Brasília: DF, v.9, n.47,p.13-19, 1990.

CASTANHO, Sérgio. Teoria da história e história da educação: por uma história cultural não culturalista. Campinas, SP: Autores Associados, 2010.

CELLARD, André. A análise documental. In: POUPART, Jean et al. A pesquisa qualitativa: enfoques epistemológicos e metodológicos. Petrópolis: Vozes, 2008

CIAVATTA, Maria. O conhecimento histórico e o problema teórico-metodológico das mediações. In: FRIGOTTO, Gaudêncio \& CIAVATTA, Maria (org.). Teoria e educação no labirinto do capital. São Paulo: Expressão Popular, 2014.

CHAVES, Vera Lucia Jacob. Expansão da privatização/mercantilização do ensino superior brasileiro: a formação dos oligopólios. In: Revista Educação e Sociedade, Campinas, v. 31, n. 111, p. 481-500, abr.-jun. 2010.

COSTA PINTO, L. A. Sociologia \& Desenvolvimento. Rio de Janeiro: Civilização Brasileira, 1978.

EVANGELISTA, Olinda (org.). O que revelam os slogans na política educacional. Araraquara-SP: Junqueira \& Marin, 2014.

FONTES, Virginia. História e Verdade. In: FRIGOTTO, Gaudêncio; CIAVATTA, Maria (orgs.). Teoria e Educação no Labirinto do Capital. Petrópolis, R.J.: Vozes, 2001. p.107 $-120$.

FRIGOTTO, Gaudêncio. O enfoque da dialética materialista histórica na pesquisa educacional. In: CIAVATTA, Maria (org.). Gaudêncio Frigotto: um intelectual crítico nos pequenos e nos grandes embates. Belo Horizonte: Autêntica Editora, 2012. p. 159 -176 .

GORENDER, Jacob. Apresentação. In: MARX, K. O Capital: Crítica da economia política. 2 ed. São Paulo: Nova Cultura, 1985. p. 7- 57.

HARVEY, David. Condição pós-moderna. São Paulo: Loyola, 2004.

JAPIASSU, Hilton. Introdução. In: O Mito da Neutralidade Científica. R.J: Imago,1975. p.8 - 18.

JELIN, Elizabeth. Los trabajos de la memória. Lima: IEP, 2012.

KOSIK, Karel. Dialética do concreto. Rio de Janeiro: Paz e terra, 1995. 
LE GOFF, Jacques. A História Nova. Tradução Eduardo Brandão. S. P.: Martins Fontes, 1993.

LOWY, Michael. Método Dialético e Teoria Política. Tradução de Reginaldo Di Piero. 4 ed. R.J.: Paz e Terra, 1989.

MARX, Karl; ENGELS, Friedrich. A ideologia alemã. São Paulo: Hucitec, 1999.

Manifesto do Partido Comunista. Petrópolis; Vozes, 1997.

MARX, Karl. Contribuição à crítica da economia política. São Paulo: Martins Fontes, 1983.

MAZZUCCHELLI, Frederico. A contradição em processo: o capitalismo e suas crises. São Paulo: Brasiliense, 1985.

MILLS, Charles Wright. Apêndice: Do artesanato intelectual. In:

A imaginação sociológica. 6ª edição. Tradução de Waltensir Dutra. Rio de Janeiro: Zahar, 1982. p.211243

MORAES, Maria Célia M. de. Pontos de investigação, teoria e método em uma pesquisa histórica em educação. Revista Educação \& Sociedade, Papyrus/Cedes. Campinas, S.P., ano XVII, n.65, p. 263-281, ago., 1996.

NOMA, Amélia Kimiko; KOEPSEL, Eliana Cláudia Navarro; CHILANTE, Edineia Fátima Navarro. Trabalho e educação em documentos de políticas educacionais. In: Revista HISTEDBR online, Campinas, número especial, p. 65-82, ago. 2010.

OLIVEIRA, Paulo de Salles. Metodologia das Ciências Humanas (org.). S.P.: Hucitec/UNESP,1998.

PAULO NETTO, José. Introdução ao estudo do método de Marx. São Paulo: Expressão Popular, 2011. Disponível em: <http://www.gepec.ufscar.br/publicacoes/livrose-colecoes/livros-diversos/introducao-aos-estudos-do-metodo-de-marx-j-pnetto.pdf>Acesso em: 30/05/2019.

SCHAFF, Adam. História e Verdade. Tradução Maria Paula Duarte. 5 ed. S.P.: Martins Fontes, 1991.

SHIROMA, Eneida Oto; CAMPOS, Roselane Fátima; GARCIA, Rosalba Maria Cardoso. Decifrar textos para compreender a política: subsídios teórico-metodológicos para análise de documentos. In: Revista Perspectiva, Florianópolis, v. 23, n. 02, p. 427-446, jul./dez. 2005.

TONET, Ivo. Método científico: uma abordagem ontológica. São Paulo: Instituto Lukács, 2013.

WARDE, Mirian Jorge. Contribuições da História para a Educação. Revista Em Aberto, Brasília: DF, v.9, n.47, p.3-11, 1990. 